Letter to the Editor

Carta ao Editor

Ana Paula Machado Goyano Mac Kay'

\section{Executive functions and aging}

Executive functions (EF) may be explained as the ability to plan, organize and perform intentional behavior. They refer to high level cognitive processes associated to working memory, sustained attention, dominant responses inhibition, planning and monitoring performance and activities, objective maintenance, objective and task initiation and cognitive flexibility ${ }^{(1,2)}$. They include volition, planning, purposive action and effective performance. Necessary for individual independence, they involve metacognition, metalinguistic and behavior regulation. The EF assessment depends on other cognitive processes such as attention, visual and spatial abilities, working memory and processing rate.

Language skills and executive functions interact during human development and the effects of this interaction may change over the years. For example, bilinguals experienced in controlling attention to two language systems demonstrate better inhibiting predominant responses and global set shifting. Deficits in executive functioning can be seen in difficulties with problem solving associated to novel and complex material, difficulties in determining relevant from irrelevant information, planning, organizing and responding appropriately to situations where mental flexibility is required.

Neuroimaging studies present evidence in support of the multi-faceted nature of executive functions, because different components of EF rely not only on different prefrontal areas but also in other areas of the brain. Normal human aging is associated with atrophy of the frontal lobes (prefrontal cortex and limbic system), which is related to $\mathrm{EF}$ deterioration since these cerebral sites mediate executive functioning processes ${ }^{(2-4)}$.

Research has shown that with age, mainly after 70 years, there is a decline in the ability to form concepts, to abstract and in mental flexibility. For example, senescence also has its consequences on inhibiting automatic responses while processing a novel one and in inductive reasoning on familiar topics; explaining proverbs meaning and appreciating similarities do not vary throughout the years ${ }^{(4)}$. However, there are quite often changes in EF, measured by means of neuropsychological tests, not corresponding to poor behavior in EF tasks that are part of everyday life.

Although discourse production and comprehension (one of the most important forms of communication) represent complex language processes that implicate higher order cognitive skills, research literature has privileged other aspects of aging changes. The pragmatic-functional paradigm proposes language studies under the perspective of context use and interlocutors. In this sense, natural metalanguage, which allows language flexible use, control and adaptation in different communication contexts, may indicate how executive functions articulate with natural verbal behavior.

Understanding age-related linguistic and cognitive changes will help to associate neurobiological theories of aging with theories of cognitive linguistic aging, which take

\footnotetext{
${ }^{1}$ Universidad Santo Tomas - Viña del Mar, Chile.

Financial support: none.
}

Conflict of interests: nothing to declare.
Correspondence address:

Ana Paula Machado Goyano Mac Kay Universidad Santo Tomas

Av. Limonares, 190, Vina del Mar, Chile, CEP: 2520000

E-mail: anamachadogoyanoma@

santotomas.cl

Received: March 10, 2016 
into account that executive function relies on prefrontal cortex that carries its controlling influence via considerable reciprocal connections with posterior areas.

Speech pathology and audiology investigation and practice based on evidence allow a broader understanding of communication disorders, providing novel knowledge to health sciences. Studies of verbal communication and its relation to executive functioning may contribute to a better orientation on promoting healthy aging.

The construction of novel knowledge paths is challenging! I thank the editors for the opportunity to comment upon a subject of relevance to our profession.

\section{REFERENCES}

1. Lezak MD, Howieson DB, Loring DW, Hannay HJ, Fischer JS. Neuropsychological assessment. 4th ed. New York: Oxford University Press; 2004.

2. Stuss DT, Knight RT, editors. Principles of frontal lobe function. New York: Oxford University Press; 2002.
3. Miyake A, Friedman NP, Emerson MJ, Witzki AH, Howerter A, Wager TD. The unity and diversity of executive functions and their contributions to complex "Frontal Lobe" tasks: a latent variable analysis. Cognit Psychol. 2000;41(1):49-100. http://dx.doi.org/10.1006/cogp.1999.0734. PMid:10945922.

4. Harada NC, Natelson MC, Triebel K. Normal cognitive aging. Clin Geriatr Med. 2013;29(4):737-52. http://dx.doi.org/10.1016/j.cger.2013.07.002. PMid:24094294. 